\title{
Identification of Modified and Unmodified Lipophilic B-Diketones Using Electrospray Ionisation Mass Spectrum (Esi-Ms)
}

\author{
Kaana Asemave* \\ Department of Chemistry, Benue State University, Nigeria
}

Received: 㭗 February 15, 2018; Published: 㭗 March 01, 2018

*Corresponding author: Kaana Asemave, Department of Chemistry, Benue State University, Nigeria, Tel Tel: 234 (0) 8154449231 ; Email: kasemave@gmail.com

\begin{abstract}
Identification of modified and unmodified lipophilic $\beta$-dketone was carried out successfully using positive ion mode of ESI-MS. The ESI-MS spectra were obtained using LC - Agilent 1260 Infinity with MS - Bruker micro OF time of flight MS in mass range of m/z 200-900, capillary voltage $4500 \mathrm{~V}$, nebuliser pressure $21.8 \mathrm{psi}$, dry gas flow $8 \mathrm{~L} / \mathrm{min}$ and dry gas temp $433 \mathrm{~K}$. Potassium adduct ion $503.4437 \mathrm{~m} / \mathrm{z}$ was found for the 14,16-Hentriacontanedione (Htd); whereas, the itaconate modified Htd (Ita) gave a confirmatory sodium species $645.5051 \mathrm{~m} / \mathrm{z}$. The ion $589.4794 \mathrm{~m} / \mathrm{z}$ was for potassium species of the singly added acrylate modified Htd (Mas). Meanwhile, the doubly added acrylate modified Htd (Mad) formed the potassium adduct ion of $675.5179 \mathrm{~m} / \mathrm{z}$. However, protonated species for these molecules were not obtained.
\end{abstract}

Keywords: Electrospray ionisation mass spectrum (ESI-MS); Modified and unmodified lipophilic $\beta$-diketone

\section{Introduction}

Electrospray ionization mass spectroscopic technique (ESIMS) has already been established as a powerful tool in the characterization of small and large molecules [1]. ESI concept was firstly introduced in 1968 by Dole [2]. It is a less energetic ionization technique, where a sample is protonated in gas phase to form cationic species; not radical (as is the case of impact ionization approach), [3] thus causing little or no fragmentation of the parent compound. It is pertinent to make do with ESI-MS because, in some cases, the column in GC is not suitable for detecting very high molecular weight organic compounds. Literature report has it that, ESI-MS method is reliable, robust and much less time consuming than the GC methods [4]. Importantly, ESI-MS is simple, fast, accurate, sensitive and straightforward technique for the analyzing compounds [5,6]. Alternative techniques for analyses of compounds such as NMR need further processing and requisite expertise to enable the identification of a compound.

Thus, the interfacing of electrospray ionization with modern mass spectrometers has been applied to estimating the molecular weights of many compounds [6]. It is useful to determine molecular weight of organic molecules even at femtomole level. Hence,
Knepper [4] also reported electrospray mass spectrometry as a simple, sensitive and quick method for the determination of polar organic traces in water samples without derivatization. Electrospray ionization mass spectrometry was used to develop a rapid, sensitive and accurate method for determination and identification of hepatotoxic microcystins, cyanobacterial cyclic heptapeptides [5]. Poon [6] reported a simple, fast and sensitive way of identification of anticancer drugs and their analogues consisting of organic and organometallic compounds using ESIMS. The studies suggested that ESI-MS is an effective technique for identification of organometallic and small organic compounds [6] Loss of fragments were observed from the ESI-MS spectra of the anticancer drugs. Kaltashov [7] investigated the structure, dynamics and function of metalloproteins with ESI-MS.

This method has also been used to identify major phenolic compounds present in strawberry fruits [8]. Sun [9] reported the application of ESI-MS in the identification of non-phenolic compounds in red wines as well. Phenolic compounds profile in wild edible greens was also detected with ESI-MS as reported by Barros [10] Identification of phenolic compounds in rapeseed meals were 
ascertained with ESI-MS [11]. In this studies, the molecular weight were predominantly detected in the form of $[\mathrm{M}+\mathrm{H}]^{+}[11]$. ESI-MS was also applied successfully for the qualitative analysis of green tea extract [12]. Quantitative analysis of docetaxel in polymeric matrices of poly (lactide-co-glycolide) and poly (lactide-co-glycolide)- poly (ethylene glycol) nanoparticles has been reported using ESI-MS [13]. It was observed that there was more intense formation of $[\mathrm{M}+\mathrm{H}]^{+}$than $[\mathrm{M}+\mathrm{Na}]^{+}[13]$. In as much as ESI-MS has become a global method for qualitative and quantitative analyses, there are no literature on the ESI-MS analyses of lipophilic $\beta$-diketones and there derivatives. Hence, this paper reports the identification of
14, 16-hentriacontanedione (Htd), acrylate modified Htd (Ma) and itaconate modified Htd (Ita) for the first time.

\section{Material and Methods}

About $20 \mathrm{mg}$ of each sample was prepared in methanol: water (1:1). Their ESI-MS spectra were obtained using LC - Agilent 1260 Infinity with MS - Bruker micrOTOF time of flight MS in mass range of $\mathrm{m} / \mathrm{z} 200-900$ positive ion mode, capillary voltage $4500 \mathrm{~V}$, nebuliser pressure $21.8 \mathrm{psi}$, dry gas flow $8 \mathrm{~L} / \mathrm{min}$ and dry gas temp 433K. The following chemicals in Figure 1 whose ESI-MS spectra were studied were prepared and purified prior to these studies.

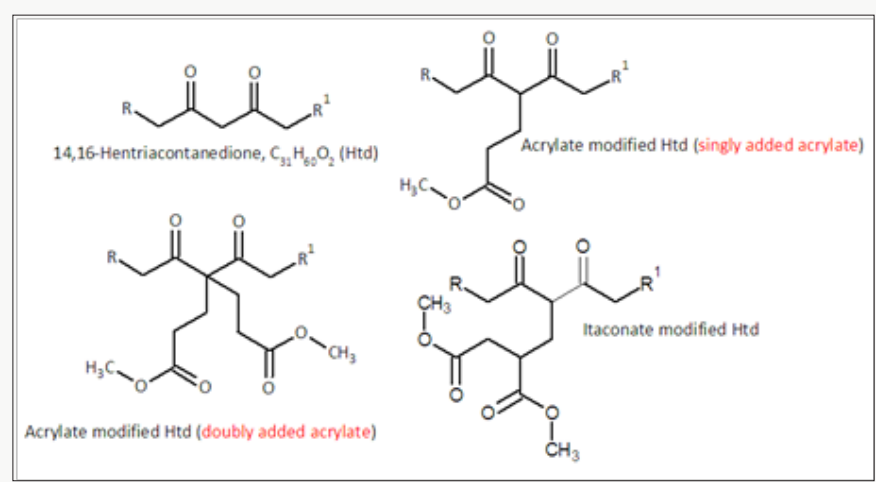

Figure 1: The lipophilic $\beta$-diketone and its derivatives.

\section{Results and Discussion}

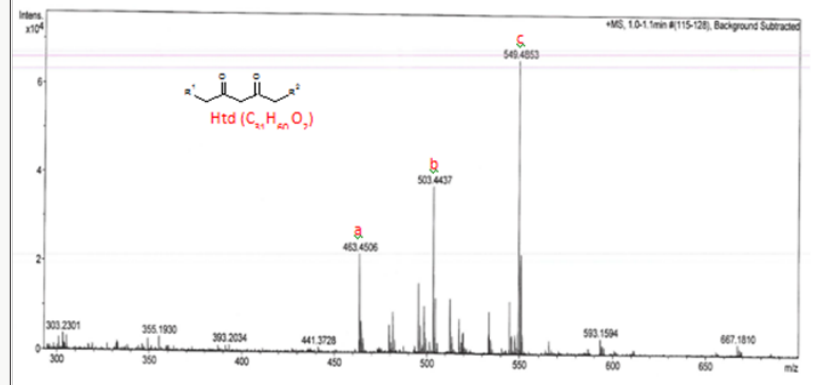

Figure 2: ESI-MS(+) for the Htd.

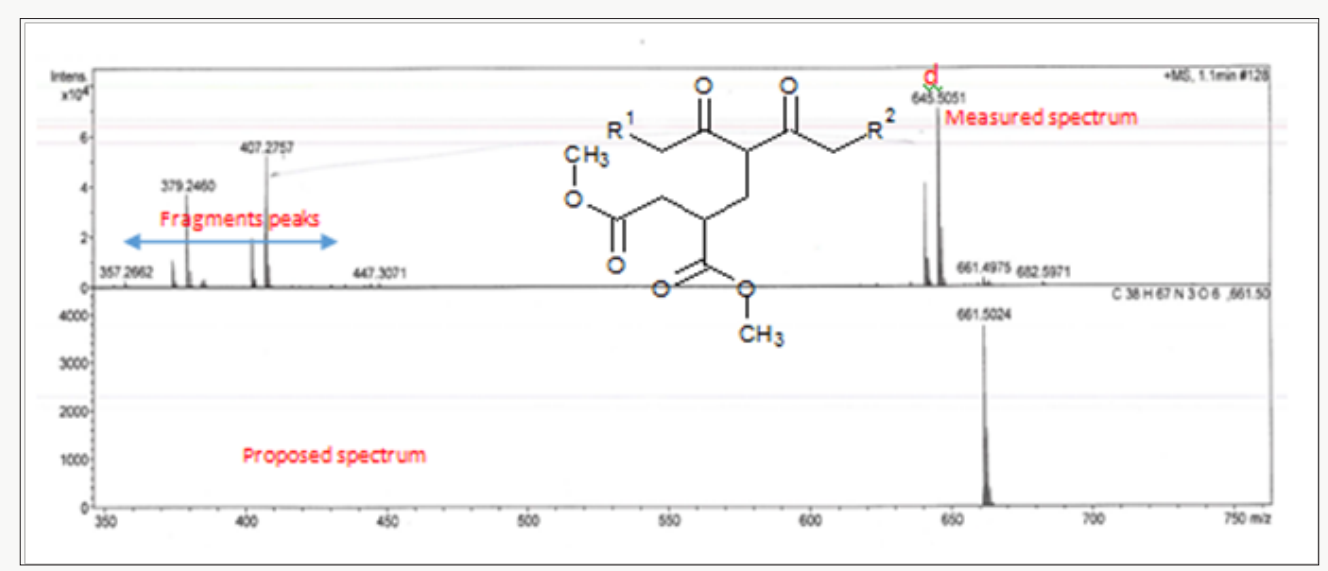

Figure 3: ESI(+)-MS of Ita. 
The unmodified Htd was firstly identified using the ESI-MS technique. Proton, potassium and copper adduct species of the Htd have been identified in the ESI-MS spectrum shown in Figure 2 and further described in Table 1 below. Copper is accounted for in this spectrum since it comes from the cuprous acetate used to isolate the long chain Htd. Aravindhan [14] reported Na species of the metal and azo-metals complexes of embelin in their ESI-MS analysis [14]. In a similar vein, the modified Htd were identified with this technique. The ESI (+)-MS of the itaconate modified Htd obtained is presented in Figure 3 and the peaks are interpreted/ assigned in Table 2. The ESI (+)-MS of this itaconate modified 14,16-hentriacontanedione (Ita) had minor peaks (i.e. less intense peaks), $407.2757 \mathrm{~m} / \mathrm{z}$ and $379.2460 \mathrm{~m} / \mathrm{z}$ in addition to the major sodium adduct peak, $645.5051 \mathrm{~m} / \mathrm{z}(\mathrm{M}+\mathrm{Na})^{+}$. The $407.2757 \mathrm{~m} / \mathrm{z}$ ion is due to loss of $239\left(\mathrm{C}_{16} \mathrm{H} 3_{10}\right)$ from the product peak $(645.5051 \mathrm{~m} / \mathrm{z})$. However, if the loss of $\mathrm{C} 16 \mathrm{H} 310$ occasioned from the parent molecule of Ita $(622 \mathrm{~m} / \mathrm{z})$, then $383 \mathrm{~m} / \mathrm{z}$ will be produced. This fragment $383 \mathrm{~m} / \mathrm{z}$ would have combined with $\mathrm{Na}^{+}$to produce $407.2757 \mathrm{~m} / \mathrm{z}$. Then, $379.2460 \mathrm{~m} / \mathrm{z}$ may have come from losses of $211\left(\mathrm{C}_{15} \mathrm{H}_{31}\right)$ and 32 $(\mathrm{MeOH})$ from the Ita $(622 \mathrm{~m} / \mathrm{z})$. Alternatively, loss of CO (28) from the $407.2757 \mathrm{~m} / \mathrm{z}$ ion could also form $379.2460 \mathrm{~m} / \mathrm{z}$. Loss of CO in such compounds has been previously reported by Brent [15] see Figure 4 which describes the possible fragmentation pattern of the lipophilic $\beta$-diketone derivatives.

Table1: ESI-MS(+) interpretation of the Htd.

\begin{tabular}{|c|c|c|}
\hline Sample & m/z peak & Interpretation \\
\hline & $464(\mathrm{a})$ & {$[\mathrm{M}]+$} \\
\hline 14,16-hentriacontanedione (C31H6002) & $503.4437(\mathrm{~b})$ & {$[\mathrm{M}+\mathrm{K}]+$} \\
\hline & $549.4853(\mathrm{c})$ & {$[(\mathrm{Htd}-\mathrm{Cu})++\mathrm{Na}-\mathrm{H}]+$} \\
\hline
\end{tabular}

Table 2: The major ESI-MS peaks and interpretation for the Ma and Ita.

\begin{tabular}{|c|c|c|c|c|}
\hline Cationic species & Peaks (m/z) & Molecular weight & Interpretation & Cross Ref. \\
\hline$[\mathrm{Ms}+\mathrm{K}]+$ & 589.4794 & $564(\mathrm{M})$ & Htd & Figure $5(\mathrm{c})$ \\
\hline$[\mathrm{Md}+\mathrm{K}]+$ & 675.5179 & 636 & $\begin{array}{c}\text { singly added acrylate }- \\
\text { Mas }\end{array}$ & Figure 5(a) \\
\hline$[\mathrm{Md}+\mathrm{Na}]+$ & 659.5216 & 636 & $\begin{array}{c}\text { Mad } \\
\text { doubly added acrylate }-\end{array}$ & Figure 5(b) \\
\hline$[\mathrm{M}+\mathrm{Na}]+$ & 645.5051 & 622 & $\begin{array}{c}\text { singly added of itaconate- } \\
\text { Ita }\end{array}$ & Figure 3(d) \\
\hline
\end{tabular}

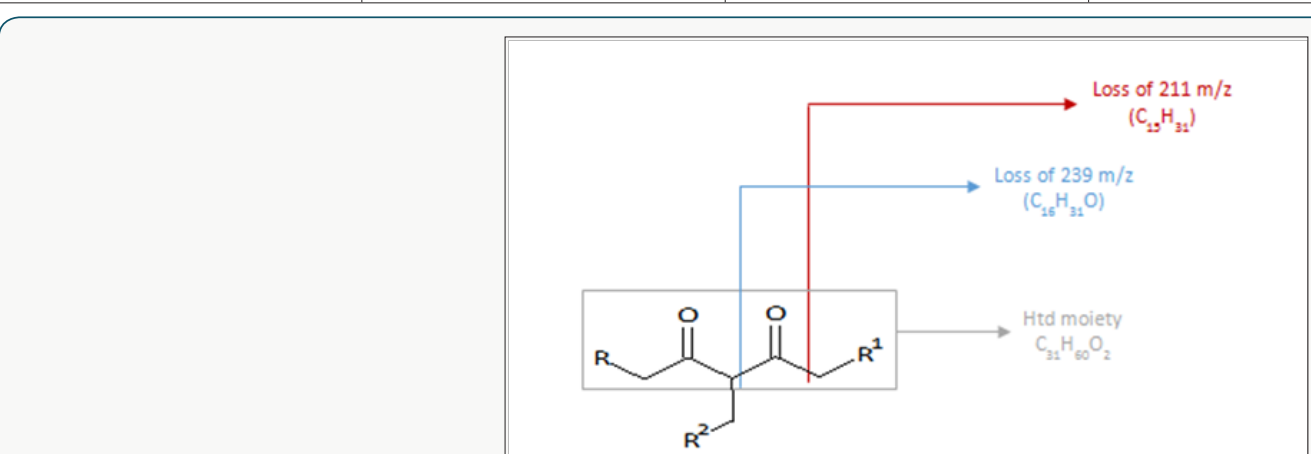

Figure 4: Proposed dissociation (fragmentation) of Htd derivatives as found in ESI-MS(+).

Similarly, sodium and potassium adducts were seen in the ESIMS of the acrylate modified $\beta$-diketone (Ma) as presented in ESIMS of Figure 5. The ESI (+)-MS spectrum of Ma had major peaks; $589.4794 \mathrm{~m} / \mathrm{z}$ and $675.5179 \mathrm{~m} / \mathrm{z}$ for potassium adducts of singly $[\mathrm{Ms}+\mathrm{K}]+$ and doubly $[\mathrm{Md}+\mathrm{K}]^{+}$added acrylate products respectively; then $659.5216 \mathrm{~m} / \mathrm{z}$ as sodium species of doubly added methyl acrylate product. Please refer to Table 2 for detail descriptions. The minor peaks $421.2924 \mathrm{~m} / \mathrm{z}, 449.3213 \mathrm{~m} / \mathrm{z}$ and $479.2984 \mathrm{~m} / \mathrm{z}$ in the ESI-MS of the Ma are likely due to formation of these species; $\left[\mathrm{M}_{\mathrm{d}}-239+\mathrm{Na}\right]^{+},\left[\mathrm{M}_{\mathrm{d}}-211+\mathrm{Na}\right]^{+}$and $\left[\mathrm{M}_{\mathrm{d}}-239+2 \mathrm{Na}+\mathrm{K}-2 \mathrm{H}\right]+$. In all these spectra, protonated species $[\mathrm{M}+\mathrm{H}]^{+}$common in ESI(+)- MS were absent as it has been similarly reported [16] Although other researchers have confirmed predominant formation of protonated species in such studies [11,13]. Furthermore, RamarosonRaonizafinimanana [17] had also observed similar fragmentation of such lipophilic $\beta$-diketones as it was found in the mass spectrum of 2,4-diketone silyl ether derivatives described in Figure 6. According to Leenheer [16] the ESI (+)-MS of fulvic acid has been shown to loss $\mathrm{CO}, \mathrm{COO}, \mathrm{H}_{2} \mathrm{O}$, carbon and proton. Furthermore, Brent [15] reported losses of $\mathrm{COO}(\mathrm{m} / \mathrm{z} 44), \mathrm{H}_{2} \mathrm{O}$ (m/z 18), $\mathrm{CO}$ (m/z 28) or combinations 
of losses $\mathrm{CO}$ and ${ }_{\mathrm{H} 2} \mathrm{O}(\mathrm{m} / \mathrm{z} 46), \mathrm{COO}$ and $\mathrm{H}_{2} \mathrm{O}(\mathrm{m} / \mathrm{z} 62)$ in coupled IC/ESI-MS/MS characterization of branched aliphatic monoacids, branched and straight chain aliphatic diacids. These show that group of atoms could be lost even from soft ESI-MS technique.
Thus in addition to the to the product peaks, $407.2757 \mathrm{~m} / \mathrm{z}$ and $379.2460 \mathrm{~m} / \mathrm{z} ; 421.2924 \mathrm{~m} / \mathrm{z}, 449.3213 \mathrm{~m} / \mathrm{z}$ and $479.2984 \mathrm{~m} / \mathrm{z}$ were observed in the Ita and Ma molecules respectively.

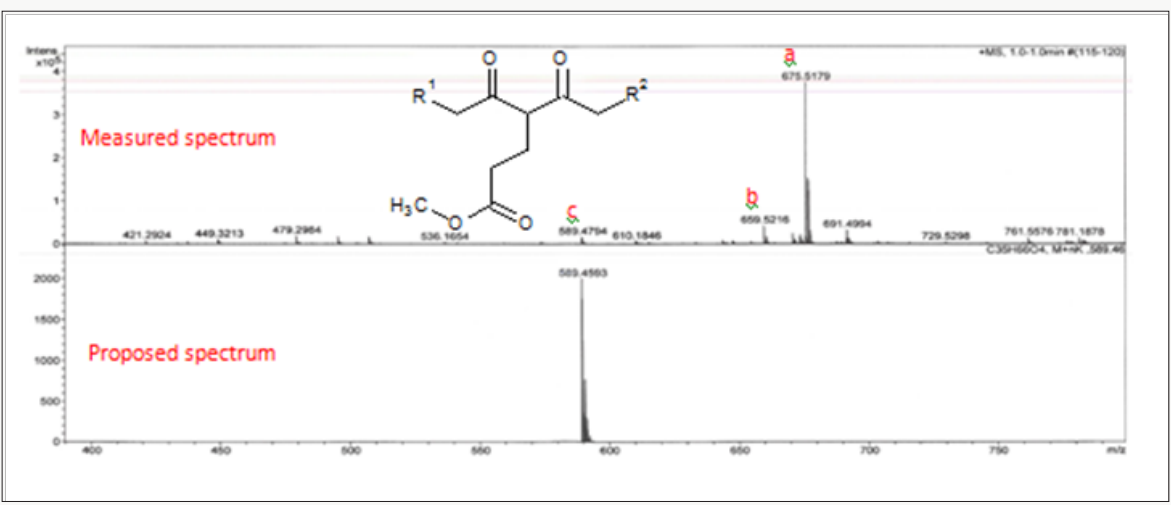

Figure 5: ESI (+)-MS of the Ma.

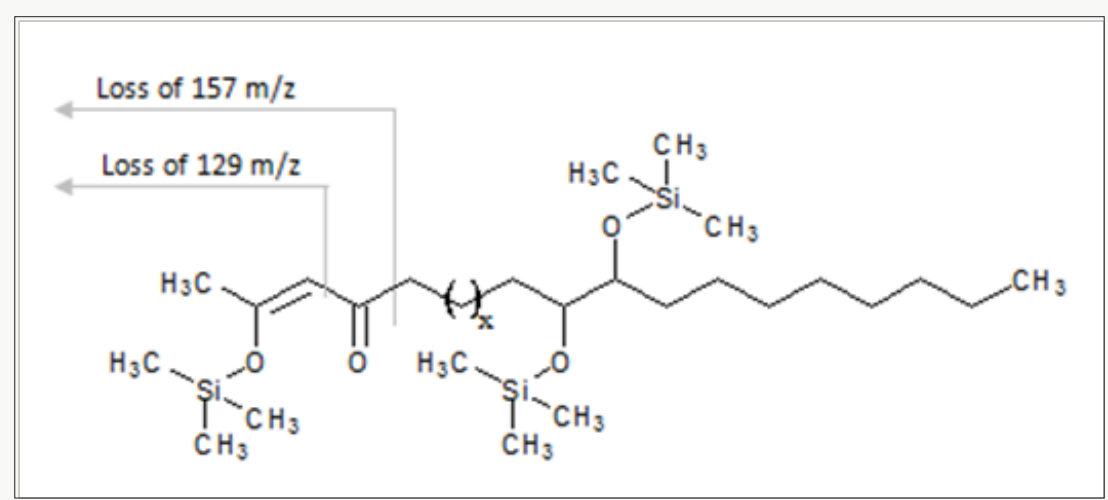

Figure 6: Fragmentation of long chain 2,4-diketone silyl ether derivatives.

\section{Conclusion}

Identification of modified and unmodified lipophilic $\beta$-dketone was carried out successfully using positive ion mode of ESI-MS. Potassium adduct ion $503.4437 \mathrm{~m} / \mathrm{z}[\mathrm{M}+\mathrm{K}]^{+}$was found for the 14,16-Hentriacontanedione (Htd); the itaconate modified Htd (Ita) gave a confirmatory sodium species $645.5051 \mathrm{~m} / \mathrm{z}[\mathrm{M}+\mathrm{Na}]^{+}$. The ion $589.4794 \mathrm{~m} / \mathrm{z}[\mathrm{Ms}+\mathrm{K}]^{+}$was for potassium species of the singly added acrylate modified Htd (Mas). Meanwhile, the doubly added acrylate modified Htd (Mad) formed the potassium adduct of $675.5179 \mathrm{~m} / \mathrm{z}\left[\mathrm{M}_{\mathrm{d}}+\mathrm{K}\right]^{+}$. However, protonated species for these molecules were not obtained.

\section{Acknowledgements}

We thank the TET Fund Nigeria for the grant.

\section{References}

1. Laughlin S, Wilson WD (2015) May the Best Molecule Win Competition ESI Mass Spectrometry. Int J Mol Sci 16(10): 24506-24531.

2. Dole M, Mack LL, Hines RL, Mobley RC, Ferguson LD (1968) Molecular Beams of Macroions. Chem Phys 49(5): 2240-2249.

3. Parsons AF (2003) Keynotes in organic chemistry. Blackwell publishing.
4. Knepper TP, Werner A, Bogenschütz G (2005) Determination of synthetic chelating agents in surface and waste water by ion chromatography mass spectrometry. J Chromatogr A 1085(2): 240-246.

5. Yuan M, Namikoshi M, Otsuki A (1999) Electrospray Ionization Mass Spectrometric Analysis of Microcystins, Cyclic Heptapeptide Hepatotoxins Modulation of Charge States and $[\mathrm{M}+\mathrm{H}]^{+}$to $[\mathrm{M}+\mathrm{Na}]^{+}$Ratio. J Am Soc Mass Spectrom 10(11): 1138-1151.

6. Poon GK, Bisset GMF, Mistry P (1993) Electrospray Ionization Mass Spectrometry for Analysis of Low Molecular Weight Anticancer Drugs and Their Analogues. J Am Sos Mass Spectom 4(7): 588-595.

7. Kaltashov IA, Zhang M, Eyles SJ, Abzalimov RR (2006) Investigation of structure, dynamics and function of metalloproteins with electrospray ionization mass spectrometry. Anal Bioanal Chem 386(3): 472-478.

8. Seeram NP, Lee R, Scheuller HS, Heber D (2006) Identification of phenolic compounds in strawberries by liquid chromatography electrospray ionization mass spectroscopy. Food Chem 97(1): 1-11.

9. Sun J, Liang F, Bin Y, Li P, Duan C (2007) Screening Non-colored Phenolics in Red Wines using Liquid Chromatography/Ultraviolet and Mass Spectrometry/Mass Spectrometry Libraries. Molecules 12(3): 679-693.

10. Barros L, Dueñas M, Ferreira ICFR, Carvalho AM, Santos Buelga C: Phenolic compounds profile in wild edible greens from Portugal obtained by HPLC-DAD-ESI/MS.

11. Yang S, Arasu MV, Chun J, Jang Y, Lee Y, et al. (2015) Identification and Determination of Phenolic Compounds in Rapeseed Meals (Brassica napus L.). J Agric Chem Environ 4(1): 14-23. 
12. Savić IM, Nikolić VD, Savić IM, Nikolić LB (2014) The Qualitative Analysis Of The Green Tea Extract Using Esi-Ms Method. Adv Technol 3: 30-37.

13. Rafiei P, Michel D, Haddadi A (2015) Application of a Rapid ESI-MS/MS Method for Quantitative Analysis of Docetaxel in Polymeric Matrices of PLGA and PLGA-PEG Nanoparticles through Direct Injection to Mass Spectrometer. Am J Anal Chem 6(2): 164-175.

14. Aravindhan R, Sreelatha T, Perumal PT, Gnanamani A (2014) Synthesis characterization and biological profile of metal and azo-metal complexes of embelin. Complex met (Taylors Fr. 7-79).

15. Brent LC, Reiner JL, Dickerson RR, Sander LC (2014) Method for
Characterization of Low Molecular Weight Organic Acids in Atmospheric Aerosols Using Ion Chromatography Mass Spectrometry. Anal Chem 86(15): 7328-7336.

16. Leenheer JA, Rostad CE, Gates PM, Furlong ET, Ferrer I (2001) Molecular Resolution and Fragmentation of Fulvic Acid by Electrospray Ionization/ Multistage Tandem Mass Spectrometry. Anal Chem 73(7): 1461-1471.

17. Ramaroson Raonizafinimanana B, Gaydou EM, Bombarda I (2000) Long Chain Aliphatic $\beta$-Diketones from Epicuticular Wax of Vanilla Bean Species Synthesis of Nervonoylacetone. J Agric Food Chem 48(10): 4739-4743.

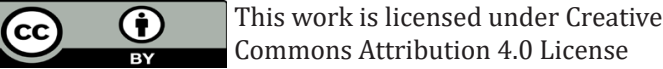

To Submit Your Article Click Here:

Submit Article

DOI: 10.32474/AOICS.2018.02.000127

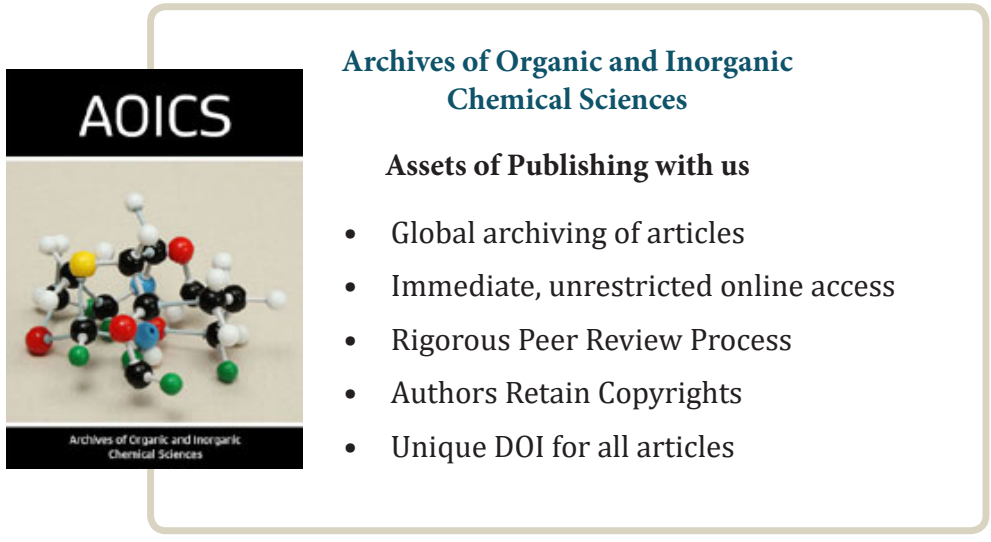

